Pacific Journal of Mathematics

MULTIPLICITY AND THE AREA OF AN $(n-1)$ CONTINUOUS 


\title{
MULTIPLICITY AND THE AREA OF AN $(n-1)$ CONTINUOUS MAPPING
}

\author{
RONALD GARIEPY
}

For a class of mappings considered by Goffman and Ziemer [Annals of Math. $92(1970)$ ] it is shown that the area is given by the integral of a multiplicity function and a convergence theorem is proved.

1. Introduction. A theory of surface area for mappings beyond the class of continuous mappings was initiated in [2]. This theory includes certain essentially discontinuous mappings for which it seems natural that the area be given by the classical integral formula.

Let $Q=R^{n} \cap\left\{x: 0<x_{i}<1\right.$ for $\left.1 \leqq i \leqq n\right\}$. For each $i \in\{1, \cdots, n\}$ and $r \in I=\{t: 0<t<1\}$ let $P_{i}(r)=Q \cap\left\{x: x_{i}=r\right\}$. A mapping $f: Q \rightarrow R^{m}$, $n \leqq m$, is said to be $n-1$ continuous if, for each $i, f \mid P_{i}(r)$ is continuous for almost every (in the sense of 1-dimensional Lebesgue measure) $r \in I$. $A$ sequence $\left\{f_{j}\right\}$ of mappings from $Q$ into $R^{m}$ is said to converge $n-1$ to $f$ if, for each $i, f_{j} \mid P_{i}(r)$ converges uniformly to $f \mid P_{i}(r)$ for almost every $r \in I$.

The area of an $n-1$ continuous mapping $f: Q \rightarrow R^{m}$ is defined as

$$
A(f)=\inf \varliminf_{j \rightarrow \infty} a\left(f_{j}\right)
$$

where the infimum is taken over all sequences $\left\{f_{j}\right\}$ of quasilinear mappings converging $n-1$ to $f$ and $a\left(f_{j}\right)$ denotes the elementary area of $f_{j}$. In [2] it was shown that $A(f)$ coincides with Lebesgue area if $f$ is continuous.

For real $p \geqq 1$, let $W_{p}^{1}(Q)$ denote those functions in $L^{p}(Q)$ whose distribution first partial derivatives are functions in $L^{p}(Q)$. Suppose $f: Q \rightarrow R^{m}$ with $f=\left(f^{1}, \cdots, f^{m}\right)$ and $f^{i} \in W_{p_{i}}^{1}(Q), p_{i}>n-1$ for $1 \leqq i \leqq m$ and $\sum_{j=1}^{n} 1 / p_{i_{j}} \leqq 1$ whenever $1 \leqq i_{1}<\cdots<i_{n} \leqq m$. It was shown in [3] that $f$ is $n-1$ continuous and

$$
A(f)=\int_{Q}|J f(x)| d x
$$

In this paper we prove the following

THeOREM. If $f: Q \rightarrow R^{n}$ with $f^{i} \in W_{p_{i}}^{1}(Q), p_{i}>n-1$ and $\sum_{i=1}^{n} 1 / p_{i} \leqq 1$, then there is a nonnegative integer valued lower semicontinuous function $N(f, y)$ on $R^{n}$ such that

$$
A(f)=\int_{R^{n}} N(f, y) d y
$$


and, if $\left\{f_{j}\right\}$ is any sequence of quasi-linear mappings converging $n-1$ to $f$ with $A(f)=\lim _{j \rightarrow \infty} a\left(f_{j}\right)$, then

$$
\lim _{j \rightarrow \infty} \int_{R^{n}}\left|N(f, y)-N\left(f_{j}, y\right)\right| d y=0
$$

and

$$
\int_{Q} \phi(f(x)) J f(x) d x=\lim _{j \rightarrow \infty} \int_{Q} \phi\left(f_{j}(x)\right) J f_{j}(x) d x
$$

whenever $\phi$ is a continuous real valued function on $R^{n}$ with compact support.

2. Proof of (1) and (2). Suppose $f$ satisfies the hypothesis of the theorem. By a full set of hyperplanes we will mean a subset $P$ of $\left\{P_{i}(r): 1 \leqq i \leqq n\right.$ and $\left.0<r<1\right\}$ such that, for each $i, P_{i}(r) \in P$ for almost every $r \in I$.

If $\pi \subset Q$ is an $n$-cube such that $f \mid \partial \pi$ is continuous and $y \in R^{n}-f(\partial \pi)$, let $0(f, \pi, y)$ denote the topological index of $y$ with respect to the mapping $f \mid \partial \pi[4, \mathrm{p} .123]$. If $y \in f(\partial \pi)$ let $0(f, \pi, y)=0$.

Let $P$ be a full set of hyperplanes such that $f \mid P_{i}(r)$ is continuous whenever $P_{i}(r) \in P$. In harmony with [1, page 173] let, for $y \in R^{n}$,

$$
N(f, y)=\sup \sum|0(f, \pi, y)|
$$

where the supremum is taken over all finite collections $G$ of non overlapping $n$-cubes $\pi \subset Q$ whose $n-1$ faces all lie in elements of $P$. From the properties of the topological index, it is easily seen that $N(f, y)$ is a lower semicontinuous function of $y$.

If $g: Q \rightarrow R^{n}$ is quasi-linear, then $N(g, y)$ is independent of the choice of $P$ and

$$
a(g)=\int_{R^{n}} N(g, y) d y .
$$

By $[3,3.5]$ we know that $f$ possesses a regular approximate differential almost everywhere in $Q$. Using the arguments of $[1$, page 424] one verifies that

$$
\int_{Q}|J f(x)| d x \leqq \int_{R^{n}} N(f, y) d y
$$

whenever $N(f, y)$ is computed relative to a full set $P$ of hyperplanes such that the restriction of $f$ to each element of $P$ is continuous.

Suppose $\left\{f_{j}\right\}$ is a sequence of quasi-linear mappings converging $n-1$ to $f$ with $A(f)=\lim _{j \rightarrow \infty} a\left(f_{j}\right)$. Let $P$ be a full set of hyperplanes on each of which the sequence converges uniformly to $f$ and define $N(f, y)$ relative to $P$. For each $y \in R^{n}$ we have 


$$
N(f, y) \leqq \lim _{j \rightarrow \infty} N\left(f_{j}, y\right)
$$

and hence

$$
\int_{R^{n}} N(f, y) d y \leqq \lim _{j \rightarrow \infty} \int_{R^{n}} N\left(f_{j}, y\right) d y=A(f) .
$$

If $\bar{P} \subset P$ is a full set of hyperplanes and $\bar{N}(f, y)$ is defined relative to $\bar{P}$, then, clearly $\bar{N}(f, y) \leqq N(f, y)$ for all $y \in R^{n}$. Since $A(f)=$ $\int|J f(x)| d x$, it follows that $N(f, y)$ is determined as an element of $L^{1}\left(R^{n}\right)$ independent of the choice of the sequence $\left\{f_{j}\right\}$. Thus (1) is proved and (2) follows because $N(f, y)$ is integer valued and

$$
N(f, y) \leqq \lim _{j \rightarrow \infty} N\left(f_{j}, y\right)
$$

for almost every $y \in R^{n}$ whenever $\left\{f_{j}\right\}$ is a sequence of quasilinear mappings converging $n-1$ to $f$ with $A(f)=\lim _{j \rightarrow \infty} a\left(f_{j}\right)$.

Proof of (3). Suppose $f$ and $\left\{f_{j}\right\}$ satisfy the conditions of the theorem and let $P$ be a full set of hyperplanes on each of which $\left\{f_{j}\right\}$ converges uniformly to $f$.

For $y \in R^{n}$ let

$$
N^{ \pm}(f, y)=\sup \sum_{\pi \in i} \frac{1}{2}[|0(f, \pi, y)| \pm 0(f, \pi, y)]
$$

where the supremum is taken over all finite collections $G$ of non overlapping $n$-cubes $\pi \subset Q$ whose $n-1$ faces all lie in elements of $P$.

Clearly

$$
N^{ \pm}(f, y) \leqq N(f, y) \leqq N^{+}(f, y)+N^{-}(f, y) .
$$

It is readily seen that

$$
N^{ \pm}(f, y) \leqq \lim _{j \rightarrow \infty} N^{ \pm}\left(f_{j}, y\right)
$$

and that the $N^{ \pm}(f, y)$ are lower semicontinuous functions of $y$.

In case $g: Q \rightarrow R^{n}$ is quasi-linear, $N^{ \pm}(g, y)$ are independent of the choice of $P$ and

$$
N(g, y)=N^{+}(g, y)+N^{-}(g, y)
$$

for almost every $y \in R^{n}$.

For each positive integer $j$, let

$$
E_{j}^{ \pm}=\left\{y: N^{ \pm}\left(f_{k}, y\right)<N^{ \pm}(f, y) \text { for some } k \geqq j\right\} .
$$

and let $E_{j}=E_{j}^{+} \cup E_{j}^{-}$.

Since the functions $N^{ \pm}$are integer valued we have 


$$
\lim _{j \rightarrow \infty} \mathscr{L}_{n}\left(E_{j}\right)=0
$$

where $\mathscr{L}_{n}$ denotes $n$ dimensional Lebesgue measure. Now

$$
\begin{aligned}
& \int_{R^{n}}\left|N^{+}\left(f_{j}, y\right)-N^{+}(f, y)\right| d y \\
& \leqq \int_{R^{n}} N^{+}\left(f_{j}, y\right) d y-\int_{R^{n}-E_{j}^{+}} N^{+}(f, y) d y+\int_{E_{j}^{+}}(f, y) d y \\
& \leqq \int_{R^{n}}\left(N^{+}\left(f_{j}, y\right)+N^{-}\left(f_{j}, y\right)\right) d y \\
& \quad-\int_{R^{n}-E_{j}}\left(N^{+}(f, y)+N^{-}(f, y)\right) d y+\int_{E_{j}} N^{+}(f, y) d y \\
& \quad \leqq \int_{R^{n}} N\left(f_{j}, y\right) d y-\int_{R^{n_{-}} E_{j}} N(f, y) d y+\int_{E_{j}} N(f, y) d y \\
& \quad=a\left(f_{j}\right)-A(f)+2 \int_{E_{j}} N(f, y) d y .
\end{aligned}
$$

Thus

$$
\lim _{j \rightarrow \infty} \int_{R^{n}}\left|N^{ \pm}\left(f_{j}, y\right)-N^{ \pm}(f, y)\right| d y=0
$$

Now

$$
\begin{aligned}
0 \leqq & \int_{R^{n}}\left[N^{+}(f, y)+N^{-}(f, y)-N(f, y)\right] d y \\
\leqq & \int_{R^{n}}\left|N^{+}(f, y)-N^{+}\left(f_{j}, y\right)\right| d y+\int_{R^{n}}\left|N^{-}(f, y)-N^{-}\left(f_{j}, y\right)\right| d y \\
& +\int_{R^{n}}\left|N(f, y)-N\left(f_{j}, y\right)\right| d y .
\end{aligned}
$$

Thus, $N(f, y)=N^{+}(f, y)+N^{-}(f, y)$ for almost every $y \in R^{n}$.

Let $n(f, y)=N^{+}(f, y)-N^{-}(f, y)$. Then

$$
\lim _{j \rightarrow \infty} \int_{R^{n}}\left|n(f, y)-n\left(f_{j}, y\right)\right| d y=0 \text {. }
$$

Suppose $\phi$ is a real valued continuous function on $R^{n}$ with compact support. If $g: Q \rightarrow R^{n}$ is quasi-linear (or of class $C^{1}$ ) then

$$
\int_{Q} \phi(g(x)) J g(x) d x=\int_{R^{n}} \phi(y) n(g, y) d y \text {. }
$$

Suppose $\left\{\bar{f}_{j}\right\}$ is a sequence of modifiers of $f$.

Then, from $[3,3.2]$, the sequence $\left\{\bar{f}_{j}\right\}$ converges $n-1$ to $f$ and

$$
\lim _{j \rightarrow \infty} \int_{Q}\left|J f(x)-J \bar{f}_{j}(x)\right| d x=0 .
$$




$$
\begin{aligned}
& \int_{Q} \phi(f(x)) J f(x) d x=\lim _{j \rightarrow \infty} \int_{Q} \phi\left(\bar{f}_{j}(x)\right) J \bar{f}_{j}(x) d x \\
& \quad=\lim _{j \rightarrow \infty} \int_{R^{n}} \phi(y) n\left(\bar{f}_{j}, y\right) d y=\int_{R^{n}} \phi(y) n(f, y) d y .
\end{aligned}
$$

Thus

$$
\begin{gathered}
\lim _{j \rightarrow \infty} \int_{Q} \phi\left(f_{j}(x)\right) J f_{j}(x) d x=\lim _{j \rightarrow \infty} \int_{R^{n}} \phi(y) n\left(f_{j}, y\right) d y \\
=\int_{R^{n}} \phi(y) n(f, y) d y=\int_{Q} \phi(f(x)) J f(x) d x
\end{gathered}
$$

and (3) is proved.

\section{REFERENCES}

1. L. Cesari, Surface Area, Annals of Mathematics Studies No. 35, Princeton University Press, Princeton, N. J. 1956.

2. C. Goffman and F.C. Liu, Discontinuous mappings and surface area, Proc. London Math. Soc., 20 (1970), 237-248.

3. C. Goffman and W. Ziemer, Higher dimensional mappings for which the area formula holds, Annals of Math., 92 (1970), 482-488.

4. T. Rado and P. V. Reichelderfer, Continuous Transformations in Analysis, SpringerVerlag, Berlin, 1955.

Received October 26, 1971.

UNIVERSITY OF KENTUCKY 



\section{PACIFIC JOURNAL OF MATHEMATICS}

\section{EDITORS}

\section{H. SAMELSON}

Stanford University

Stanford, California 94305

C. R. Новву

University of Washington Seattle, Washington 98105

\section{J. DuGundJI}

Department of Mathematics University of Southern California Los Angeles, California 90007

RICHARD ARENS

University of California Los Angeles, California 90024

\section{ASSOCIATE EDITORS}
E. F. BECKENBACH
B. H. NeumanN
F. WOLF
K. YoSHIDA

\section{SUPPORTING INSTITUTIONS}

\author{
UNIVERSITY OF BRITISH COLUMBIA \\ CALIFORNIA INSTITUTE OF TECHNOLOGY \\ UNIVERSITY OF CALIFORNIA \\ MONTANA STATE UNIVERSITY \\ UNIVERSITY OF NEVADA \\ NEW MEXICO STATE UNIVERSITY \\ OREGON STATE UNIVERSITY \\ UNIVERSITY OF OREGON \\ OSAKA UNIVERSITY
}

\author{
UNIVERSITY OF SOUTHERN CALIFORNIA \\ STANFORD UNIVERSITY \\ UNIVERSITY OF TOKYO \\ UNIVERSITY OF UTAH \\ WASHINGTON STATE UNIVERSITY \\ UNIVERSITY OF WASHINGTON \\ $*{ }^{*}$
AMERICAN MATHEMATICAL SOCIETY
NAVAL WEAPONS CENTER
}

The Supporting Institutions listed above contribute to the cost of publication of this Journal, but they are not owners or publishers and have no responsibility for its content or policies.

Mathematical papers intended for publication in the Pacific Journal of Mathematics should be in typed form or offset-reproduced, (not dittoed), double spaced with large margins. Underline Greek letters in red, German in green, and script in blue. The first paragraph or two must be capable of being used separately as a synopsis of the entire paper. The editorial "we" must not be used in the synopsis, and items of the bibliography should not be cited there unless absolutely necessary, in which case they must be identified by author and Journal, rather than by item number. Manuscripts, in duplicate if possible, may be sent to any one of the four editors. Please classify according to the scheme of Math. Rev. Index to Vol, 39. All other communications to the editors should be addressed to the managing editor, Richard Arens, University of California, Los Angeles, California, 90024.

50 reprints are provided free for each article; additional copies may be obtained at cost in multiples of 50 .

The Pacific Journal of Mathematics is issued monthly as of January 1966. Regular subscription rate: $\$ 48.00$ a year (6 Vols., 12 issues). Special rate: $\$ 24.00$ a year to individual members of supporting institutions.

Subscriptions, orders for back numbers, and changes of address should be sent to Pacific Journal of Mathematics, 103 Highland Boulevard, Berkeley, California, 94708.

PUBLISHED BY PACIFIC JOURNAL OF MATHEMATICS, A NON-PROFIT CORPORATION

Printed at Kokusai Bunken Insatsusha (International Academic Printing Co., Ltd.), 270, 3-chome Totsuka-cho, Shinjuku-ku, Tokyo 160, Japan. 


\section{Pacific Journal of Mathematics}

\section{Vol. 44, No. $2 \quad$ June, 1973}

Tsuyoshi Andô, Closed range theorems for convex sets and linear liftings . . . . . . 393

Richard David Bourgin, Conically bounded sets in Banach spaces . . . . . . . . . 411

Robert Jay Buck, Hausdorff dimensions for compact sets in $R^{n} \ldots \ldots \ldots \ldots \ldots \ldots . \ldots 421$

Henry Cheng, A constructive Riemann mapping theorem ................ 435

David Fleming Dawson, Summability of subsequences and stretchings of

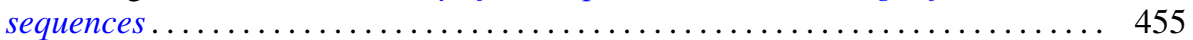

William Thomas Eaton, A two sided approximation theorem for 2-spheres ....... 461

Jay Paul Fillmore and John Herman Scheuneman, Fundamental groups of compact complete locally affine complex surfaces ....................... 487

Avner Friedman, Bounded entire solutions of elliptic equations . . . . . . . . . . . 497

Ronald Francis Gariepy, Multiplicity and the area of an $(n-1)$ continuous

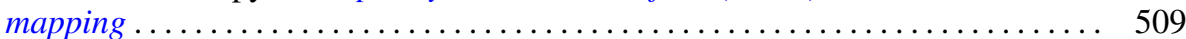

Andrew M. W. Glass, Archimedean extensions of directed interpolation groups . . . . 515

Morisuke Hasumi, Extreme points and unicity of extremum problems in $H^{1}$ on

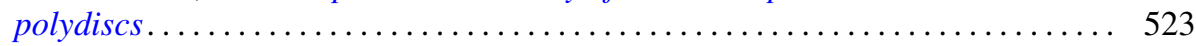

Trevor Ongley Hawkes, On the Fitting length of a soluble linear group . . . . . . 537

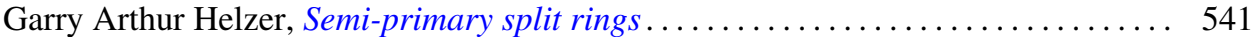

Melvin Hochster, Expanded radical ideals and semiregular ideals . . . . . . . . . 553

Keizō Kikuchi, Starlike and convex mappings in several complex variables . . . . . . 569

Charles Philip Lanski, On the relationship of a ring and the subring generated by its

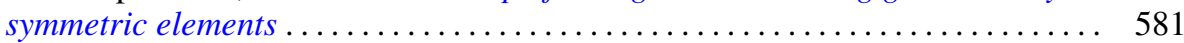

Jimmie Don Lawson, Intrinsic topologies in topological lattices and semilattices ........................................... 593

Roy Bruce Levow, Counterexamples to conjectures of Ryser and de Oliveira ...... 603

Arthur Larry Lieberman, Some representations of the automorphism group of an infinite continuous homogeneous measure algebra ..........

William George McArthur, $G_{\delta}$-diagonals and metrization theorems $\ldots .$.

James Murdoch McPherson, Wild arcs in three-space. II. An invariant of

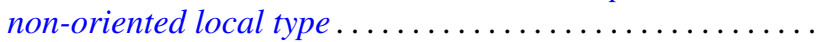

H. Millington and Maurice Sion, Inverse systems of group-valued measures ...

C. Edward Moore, Concrete semispaces and lexicographic separation of convex

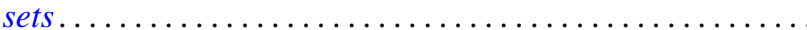

Jingyal Pak, Actions of torus $T^{n}$ on $(n+1)$-manifolds $M^{n+1}$.

Merrell Lee Patrick, Extensions of inequalities of the Laguerre and Turán type . . . . 675

Harold L. Peterson, Jr., Discontinuous characters and subgroups of finite index. . . . 683

S. P. Philipp, Abel summability of conjugate integrals . . . . . . . . . . . . . 693

R. B. Quintana and Charles R. B. Wright, On groups of exponent four satisfying an

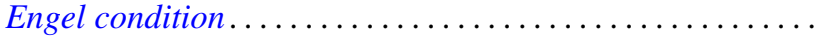

Marlon C. Rayburn, On Hausdorff compactifications. . . . . . . . . .

Martin G. Ribe, Necessary convexity conditions for the Hahn-Banach theorem in

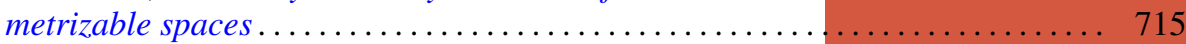

Ryōtarō Satō, On decomposition of transformations in infinite measure spaces .... 733

Peter Drummond Taylor, Subgradients of a convex function obtained from a

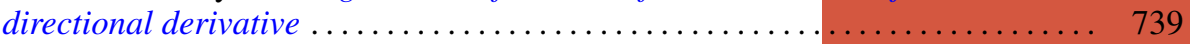

James William Thomas, A bifurcation theorem for $k$-set contractions . . . . . . . . 749 Clifford Edward Weil, A topological lemma and applications to real functions . . . . 757

Stephen Andrew Williams, A nonlinear elliptic boundary value problem . . ....... 767

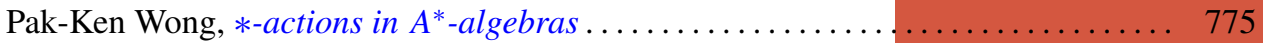

